\title{
Comparison of general anesthesia with endotracheal intubation, combined spinal- epidural anesthesia, and general anesthesia with laryngeal mask airway and nerve block for intertrochanteric fracture surgeries in elderly patients: a retrospective cohort study
}

Yang Liu', Mang Su' ${ }^{1}$, Wei Li ${ }^{1}$, Hao Yuan ${ }^{1}$ and Cheng Yang ${ }^{1 *}$ (D)

\begin{abstract}
Background: There is no consensus on the optimal anesthesia method for intertrochanteric fracture surgeries in elderly patients. Our study aimed to compare the hemodynamics and perioperative outcomes of general anesthesia with endotracheal intubation, combined spinal-epidural anesthesia, and general anesthesia with laryngeal mask airway (LMA) and nerve block for intertrochanteric fracture surgeries in elderly patients.

Methods: This is a retrospective study of 75 patients aged $>60$ years scheduled for intertrochanteric fracture surgeries with general anesthesia with intubation $(n=25)$, combined spinal-epidural anesthesia $(n=25)$, and general anesthesia with LMA and nerve block $(n=25)$. The intraoperative hemodynamics were recorded, and the maximum variation rate was calculated. Postoperative analgesic effect was evaluated using the visual analog scale (VAS). Postoperative cognitive status was assessed using the Mini-Mental State Exam (MMSE).

Results: The maximum variation rate of intraoperative heart rate, systolic blood pressure, diastolic blood pressure differed significantly between the three groups (general anesthesia with intubation > combined spinal-epidural anesthesia > general anesthesia with LMA and nerve block). The VAS scores postoperative $2 \mathrm{~h}, 4 \mathrm{~h}, 6 \mathrm{~h}$, and $8 \mathrm{~h}$ also differed significantly between the three groups (general anesthesia with intubation $>$ combined spinal-epidural anesthesia > general anesthesia with LMA and nerve block). The VAS scores postoperative $24 \mathrm{~h}$ were significantly lower in the general anesthesia with LMA/nerve block group than the general anesthesia with intubation group and the combined spinal-epidural anesthesia group. The MMSE scores postoperative $15 \mathrm{~min}$ and $45 \mathrm{~min}$ differed significantly between the three groups (general anesthesia with intubation < combined spinal-epidural anesthesia < general anesthesia with LMA and nerve block). The MMSE scores postoperative $120 \mathrm{~min}$ in the general anesthesia with intubation group were the lowest among the three groups. There was no significant difference in the incidence of respiratory infection postoperative $24 \mathrm{~h}, 48 \mathrm{~h}$, and $72 \mathrm{~h}$ between the three groups.

(Continued on next page)
\end{abstract}

\footnotetext{
* Correspondence: 358353224@qq.com

'Department of Orthopedics, Chengdu Aerospace Hospital, Chengdu

610100, China

Full list of author information is available at the end of the article
}

(c) The Author(s). 2019 Open Access This article is distributed under the terms of the Creative Commons Attribution 4.0 International License (http://creativecommons.org/licenses/by/4.0/), which permits unrestricted use, distribution, and reproduction in any medium, provided you give appropriate credit to the original author(s) and the source, provide a link to the Creative Commons license, and indicate if changes were made. The Creative Commons Public Domain Dedication waiver (http://creativecommons.org/publicdomain/zero/1.0/) applies to the data made available in this article, unless otherwise stated. 
(Continued from previous page)

Conclusion: Compared to general anesthesia with intubation and combined spinal-epidural anesthesia, general anesthesia with LMA and nerve block had better postoperative analgesic effect and less disturbances on intraoperative hemodynamics and postoperative cognition for elderly patients undergoing intertrochanteric fracture surgeries.

Keywords: Anesthesia, elderly patient, intertrochanteric fracture, laryngeal mask airway,

\section{Background}

The global population aging has led to increasingly more elderly patients with hip fractures. Aging is associated with decreased hemodynamic stability, hypertension, poor physical status, risk of cognitive impairment, and osteoporosis [1-3]. Providing anesthesia for hip fracture surgeries in elderly patients can be challenging.

It has been shown that regional anesthesia is comparable to general anesthesia for hip fractures in adults [4]. However, it is not known whether regional anesthesia is superior to general anesthesia in terms of hemodynamic stability and postoperative cognitive impairment in elderly patients undergoing hip surgeries. A previous study found that general anesthesia with endotracheal intubation was associated with intraoperative hypotension and hemodynamic instability in elderly patients undergoing hip surgeries compared to general anesthesia with laryngeal mask airway (LMA) and nerve block [5]. The effect of these two anesthetic methods on postoperative cognitive function in elderly patients is still not clear.

Our study aimed to compare intraoperative hemodynamics, postoperative pain, postoperative cognitive function, and respiratory infection between general anesthesia with endotracheal intubation, combined spinal-epidural anesthesia, and general anesthesia with LMA and nerve block for elderly patients undergoing intertrochanteric fracture surgeries.

\section{Methods \\ Patients}

A total of 75 patients scheduled for closed reduction or open reduction with internal fixation for intertrochanteric fracture between January 2017 and November 2018 were included in this retrospective study. The inclusion criteria were age $>60$ years and $<90$ years, intertrochanteric fracture diagnosed by radiology, and American Society of Anesthesiologists (ASA) physical status I-III. Patients with the following conditions were excluded: cognitive impairment, allergy to anesthetic agents, operation time $>4 \mathrm{~h}$, conversion to general anesthesia with intubation.

\section{Anesthesia protocols}

The patients were matched by sex, age, and weight and received general anesthesia with intubation $(n=$ 25), combined spinal-epidural anesthesia $(n=25)$, and general anesthesia with LMA and nerve block $(n=25)$. All patients fasted preoperatively for $8 \mathrm{~h}$. Hypertension and diabetes mellitus were controlled before the surgery. All anesthesia procedures were performed by one anesthesiologist.

For the general anesthesia with intubation, anesthesia was induced by infusing midazolam $0.05 \mathrm{mg} / \mathrm{kg}$, lidocaine $0.5 \mathrm{mg} / \mathrm{kg}$, fentanyl $3 \mu \mathrm{g} / \mathrm{kg}$, propofol $1.5-2.0 \mathrm{mg} /$ $\mathrm{kg}$, and cisatracurium $0.2 \mathrm{mg} / \mathrm{kg}$. Then the patients were intubated for mechanical ventilation.

For the combined spinal-epidural anesthesia, the patient was in the lateral decubitus position. Ropivacaine $0.5 \% 4 \mathrm{ml}$ was injected into the subarachnoid space through the L2-L3 intervertebral space. An epidural catheter was positioned. The upper level of anesthesia was controlled bellow the T8 vertebra. Ropivacaine $0.5 \%$ $3-5 \mathrm{ml}$ was administered epidurally if the surgery lasted over $2 \mathrm{~h}$.

For the general anesthesia with LMA and nerve block, lumbar plexus-sciatic nerve block was first performed. A 100-mm stimulation needle (D22G, Stimuplex, B. Braun, Germany) was used to deliver electric stimulations at 2 $\mathrm{Hz}$, with a starting current of $1 \mathrm{~mA}$ and a pulse time of $0.1 \mathrm{~ms}$. Contraction of the quadriceps femoris and the gastrocnemius in response to a current $<0.3 \mathrm{~mA}$ indicated that the injection site had been reached. After confirming no aspiration of blood or cerebrospinal fluid, ropivacaine $0.5 \% 30 \mathrm{ml}$ was injected respectively for lumbar plexus block and sciatic nerve block. Anesthesia was induced using etomidate $0.1-0.3 \mathrm{mg} / \mathrm{kg}$, vecuronium bromide $0.1 \mathrm{mg} / \mathrm{kg}$, and fentanyl $2-4 \mu \mathrm{g} / \mathrm{kg}$. Then an LMA was inserted. General anesthesia was maintained using propofol $3-5 \mathrm{mg} / \mathrm{h} \cdot \mathrm{kg}$. No postoperative analgesics were used.

\section{Collection of patient data}

Patient data was from a previous clinical trial in which intraoperative heart rate, systolic blood pressure, and diastolic blood pressure were recorded using a ventilator. Hemodynamic changes were evaluated using the maximum variation rate, which was calculated using the formula:

maximum variation rate $=($ maximum - minimum $) /$ pre - anesthesia value.

Postoperative pain was evaluated at $2 \mathrm{~h}, 4 \mathrm{~h}, 6 \mathrm{~h}, 8 \mathrm{~h}$, and $24 \mathrm{~h}$ using the visual analog scale (VAS). The VAS 
Table 1 Patient general information

\begin{tabular}{|c|c|c|c|c|}
\hline & $\begin{array}{l}\text { General anesthesia with intubation } \\
(n=25)\end{array}$ & $\begin{array}{l}\text { Combined spinal-epidural anesthesia } \\
(n=25)\end{array}$ & $\begin{array}{l}\text { General anesthesia with LMA/nerve block } \\
(n=25)\end{array}$ & $P$ \\
\hline Male, n (\%) & $12(48)$ & $10(40)$ & $11(44)$ & 0.850 \\
\hline Age, year & $74.7 \pm 6.8$ & $75.4 \pm 6.1$ & $75.5 \pm 6.0$ & 0.893 \\
\hline Weight, kg & $62.1 \pm 7.6$ & $62.3 \pm 6.4$ & $64.8 \pm 6.6$ & 0.320 \\
\hline $\begin{array}{l}\text { ASA physical status, } \\
\mathrm{n}(\%)\end{array}$ & & & & 0.796 \\
\hline । & $3(12)$ & $3(12)$ & $2(8)$ & \\
\hline$\|$ & $21(84)$ & $20(80)$ & $21(84)$ & \\
\hline III & $1(4)$ & $2(8)$ & $2(8)$ & \\
\hline Operation time (min) & $61.1 \pm 6.7$ & $62.3 \pm 6.7$ & $63.8 \pm 7.1$ & 0.782 \\
\hline $\begin{array}{l}\text { Anesthesia time } \\
\text { (time) }\end{array}$ & $85.7 \pm 6.8$ & $86.4 \pm 7.0$ & $86.6 \pm 7.0$ & 0.842 \\
\hline Hospital stay (day) & $15.7 \pm 2.2$ & $16.4 \pm 2.0$ & $14.56 \pm 2.02$ & 0.860 \\
\hline
\end{tabular}

LMA laryngeal mask airway, ASA American Society of Anesthesiologists

scores range from 0 to 10 , with 0 indicating painless and 10 indicating the worst pain imaginable.

Patient cognitive function was assessed preoperatively, postoperative $15 \mathrm{~min}, 45 \mathrm{~min}$, and $120 \mathrm{~min}$ using the Mini-Mental State Examination (MMSE). The MMSE assesses orientation to place and time, calculation, memory, language, reading, writing, and drawing. A reduction of 3 points in the postoperative MMSE score suggested postoperative cognitive dysfunction [6].

Postoperative respiratory infection was tested by bacteria culture using the respiratory secretions collected postoperative $24 \mathrm{~h}, 48 \mathrm{~h}$, and $72 \mathrm{~h}$.

\section{Statistical analysis}

Continuous data were presented as means and standard deviations. Categorical data were presented as percentages or frequencies. Comparisons were made using the one-way analysis of variance analysis followed by posthoc analysis or the chi-square test. Ordinal data was compared using the Kruskal-Wallis test. All statistical analyses were performed using the SPSS 18.0 software (SPSS, Chicago, USA). A $P$-value $<0.05$ was considered statistically significant.

\section{Results}

A total of 91 patients were eligible for inclusion and 16 patients were excluded for cognitive impairment $(n=7)$, allergy to anesthetic agents $(n=4)$, operation time $>4$ h $(n=2)$, conversion to general anesthesia with intubation $(n=3)$. The patients included 33 men and 42 women (age range, 60-90 years). There was no significant difference in sex, age, weight, and ASA physical status between the three groups (Table 1).

The maximum variation rate of heart rate, systolic blood pressure, and diastolic blood pressure differed significantly between the three groups (general anesthesia with intubation $>$ combined spinal-epidural anesthesia $>$ general anesthesia with LMA and nerve block, all $P<$ 0.001, Table 2).

The three groups showed no significant difference in preoperative VAS scores. The VAS scores postoperative $2 \mathrm{~h}, 4 \mathrm{~h}, 6 \mathrm{~h}$, and $8 \mathrm{~h}$ differed significantly between the three groups (general anesthesia with intubation $>$ combined spinal-epidural anesthesia $>$ general anesthesia with LMA and nerve block, all $P<0.001$, Table 3). The VAS scores at rest and during ambulation postoperative $24 \mathrm{~h}$ were significantly lower in the general anesthesia with LMA/nerve block group than the general anesthesia

Table 2 Comparison of intraoperative hemodynamics

\begin{tabular}{|c|c|c|c|c|}
\hline $\begin{array}{l}\text { Maximum variation } \\
\text { rate }\end{array}$ & $\begin{array}{l}\text { General anesthesia with intubation } \\
(n=25)\end{array}$ & $\begin{array}{l}\text { Combined spinal-epidural anesthesia } \\
(n=25)\end{array}$ & $\begin{array}{l}\text { General anesthesia with LMA/nerve } \\
\text { block }(n=25)\end{array}$ & $P$ \\
\hline Heart rate & $0.47(0.44-0.54)^{\#^{*}}$ & $0.31\left(0.30-0.33^{*}\right.$ & $0.22(0.21-0.24)$ & $\begin{array}{l}< \\
0.001\end{array}$ \\
\hline $\begin{array}{l}\text { Systolic blood } \\
\text { pressure }\end{array}$ & $0.45(0.39-0.48)^{\#^{*}}$ & $0.35(0.32-0.37)^{*}$ & $0.23(0.21-0.26)$ & $\begin{array}{l}< \\
0.001\end{array}$ \\
\hline $\begin{array}{l}\text { Diastolic blood } \\
\text { pressure }\end{array}$ & $0.46(0.41-0.49)^{\#^{*}}$ & $0.32(0.30-0.35)^{*}$ & $0.25(0.23-0.29)$ & $\begin{array}{l}< \\
0.001\end{array}$ \\
\hline
\end{tabular}

LMA Laryngeal mask airway. \#vs combined spinal-epidural anesthesia, $P<0.001$; ${ }^{* v s}$ general anesthesia with LMA/nerve block, $P<0.001$. 
Table 3 Evaluation of perioperative pain

\begin{tabular}{|c|c|c|c|c|}
\hline VAS score & $\begin{array}{l}\text { General anesthesia with } \\
\text { intubation }(n=25)\end{array}$ & $\begin{array}{l}\text { Combined spinal-epidural } \\
\text { anesthesia }(n=25)\end{array}$ & $\begin{array}{l}\text { General anesthesia with LMA/nerve } \\
\text { block }(n=25)\end{array}$ & $P$ \\
\hline Preoperative & $6.72 \pm 0.79$ & $6.84 \pm 0.75$ & $6.76 \pm 0.72$ & 0.849 \\
\hline Postoperative $2 \mathrm{~h}$ & $6.96 \pm 0.73^{\#^{*}}$ & $2.52 \pm 0.51^{*}$ & $1.48 \pm 0.51$ & $\begin{array}{l}< \\
0.001\end{array}$ \\
\hline Postoperative $4 \mathrm{~h}$ & $6.48 \pm 0.65^{\#^{*}}$ & $2.72 \pm 0.46^{*}$ & $1.48 \pm 0.51$ & $\begin{array}{l}< \\
0.001\end{array}$ \\
\hline Postoperative $6 \mathrm{~h}$ & $6.24 \pm 0.52^{\#^{*}}$ & $3.72 \pm 0.94^{*}$ & $2.36 \pm 0.64$ & $\begin{array}{l}< \\
0.001\end{array}$ \\
\hline Postoperative $8 \mathrm{~h}$ & $6.04 \pm 0.54^{\# *}$ & $5.44 \pm 0.77^{*}$ & $2.76 \pm 0.44$ & $\begin{array}{l}< \\
0.001\end{array}$ \\
\hline Postoperative $24 \mathrm{~h}$ at rest & $5.72 \pm 0.54^{*}$ & $6.16 \pm 0.62^{*}$ & $3.40 \pm 0.50$ & $\begin{array}{l}< \\
0.001\end{array}$ \\
\hline $\begin{array}{l}\text { Postoperative } 24 \mathrm{~h} \text { during } \\
\text { ambulation }\end{array}$ & $7.24 \pm 0.44^{*}$ & $7.16 \pm 0.37^{*}$ & $5.00 \pm 0.58$ & $\begin{array}{l}< \\
0.001\end{array}$ \\
\hline
\end{tabular}

with intubation group and the combined spinal-epidural anesthesia group.

There was no significant difference in preoperative MMSE scores between the three groups. The MMSE scores postoperative $15 \mathrm{~min}$ and $45 \mathrm{~min}$ differed significantly between the three groups (general anesthesia with intubation $<$ combined spinal-epidural anesthesia $<$ general anesthesia with LMA and nerve block, all $P<0.001$, Table 4). The MMSE scores postoperative $120 \mathrm{~min}$ in the general anesthesia with intubation group were the lowest among the three groups. However, it did not differ significantly between the combined spinal-epidural anesthesia group and the general anesthesia with LMA/ nerve block group.

There was no significant difference in the incidence of respiratory infection postoperative $24 \mathrm{~h}, 48 \mathrm{~h}$, and $72 \mathrm{~h}$ between the three groups (Table 5).

\section{Discussion}

Our study found that general anesthesia with LMA and nerve block was associated with less significant intraoperative hemodynamic variations compared to general anesthesia with intubation and combined spinal-epidural anesthesia. In addition, patients receiving general anesthesia with LMA and nerve block also had significantly less postoperative pain and significantly better postoperative cognitive function than those receiving the other two anesthesia methods.

Hemodynamic instability during intubation and extubation, such as changes in heart rate and blood pressure, can increase the risk of vascular events, especially in elderly patients [7]. In our study, patients receiving the combined spinal-epidural anesthesia also had significantly greater hemodynamic variations compared to those receiving general anesthesia with LMA and nerve block. Spinal anesthesia can inhibit the sympathetic nerves, leading to peripheral vascular dilation and hypotension [8-10]. In addition, vagus nerve dominance and slow heart rate during spinal anesthesia may also result in significant hemodynamic variations. On the contrary, general anesthesia with LMA and nerve block has been shown to have less effect on hemodynamics $[5,11,12]$.

Our study found that patients receiving general anesthesia with LMA and nerve block had generally less postoperative pain compared to those receiving general anesthesia with intubation or combined spinal-epidural anesthesia. Spinal anesthesia and nerve block both can

Table 4 Assessment of perioperative cognitive function

\begin{tabular}{|c|c|c|c|c|}
\hline MMSE score & $\begin{array}{l}\text { General anesthesia with intubation } \\
(n=25)\end{array}$ & $\begin{array}{l}\text { Combined spinal-epidural anesthesia } \\
(n=25)\end{array}$ & $\begin{array}{l}\text { General anesthesia with LMA/nerve block } \\
(n=25)\end{array}$ & $P$ \\
\hline Preoperative & $28.56 \pm 1.00$ & $28.48 \pm 0.77$ & $28.64 \pm 0.57$ & 0.780 \\
\hline $\begin{array}{l}\text { Postoperative } 15 \\
\text { min }\end{array}$ & $16.60 \pm 1.35^{\#^{*}}$ & $22.68 \pm 1.07^{*}$ & $24.72 \pm 0.98$ & $\begin{array}{l}< \\
0.001\end{array}$ \\
\hline $\begin{array}{l}\text { Postoperative } 45 \\
\text { min }\end{array}$ & $20.92 \pm 1.22^{\#^{*}}$ & $24.96 \pm 1.21^{*}$ & $27.48 \pm 0.65$ & $\begin{array}{l}< \\
0.001\end{array}$ \\
\hline $\begin{array}{l}\text { Postoperative } 120 \\
\text { min }\end{array}$ & $26.20 \pm 1.15^{\#^{*}}$ & $28.20 \pm 0.71$ & $28.48 \pm 0.59$ & $\begin{array}{l}< \\
0.001\end{array}$ \\
\hline
\end{tabular}

MMSE Mini-Mental State Exam, LMA Laryngeal mask airway. \#vs combined spinal-epidural anesthesia, $P<0.001 ;{ }^{*} v s$ general anesthesia with LMA/nerve block, $P<0.001$. 
Table 5 Perioperative respiratory infection.

\begin{tabular}{llll}
\hline & $\begin{array}{l}\text { General anesthesia with intubation } \\
(n=25)\end{array}$ & $\begin{array}{l}\text { Combined spinal-epidural anesthesia } \\
(n=25)\end{array}$ & $\begin{array}{l}\text { General anesthesia with LMA/nerve block } \\
(n=25)\end{array}$ \\
\hline $\begin{array}{l}\text { Preoperative, } \mathrm{n} \\
\text { Postoperative } 24\end{array}$ & 0 & 0 & 0 \\
$\mathrm{~h}, \mathrm{n}$ & 0 & 0 \\
$\begin{array}{l}\text { Postoperative } 48 \\
\mathrm{~h}, \mathrm{n}\end{array}$ & 2 & 1 & 0 \\
$\begin{array}{l}\text { Postoperative } 72 \\
\mathrm{~h}, \mathrm{n}\end{array}$ & 3 & 1 & 0 \\
\hline
\end{tabular}

LMA laryngeal mask airway.

effectively stop the peripheral afferent pain pathways and provide good analgesic effect. However, spinal anesthesia was not as good as lumbar plexus/sciatic nerve block in terms of analgesic effect and duration in our study. This might be explained by the relatively small doses of anesthetic agents used in spinal anesthesia, which was resulted from controlling the level of anesthesia.

The MMSE is widely used for screening cognitive dysfunction. It is easy to use and has a sensitivity of $87 \%$ and a specificity of $82 \%$ in diagnosing postoperative cognitive dysfunction [6, 13-15]. Our study found that general anesthesia with LMA and nerve block was associated with generally better postoperative cognitive function compared to general anesthesia with intubation and combined spinalepidural anesthesia. In addition, combined spinal-epidural anesthesia was also superior to general anesthesia with intubation in terms of postoperative cognitive function. We speculate that the relatively poor postoperative cognitive function of patients receiving general anesthesia with intubation was associated with the residual systemic analgesics, which might inhibit the central nervous system [16-19]. In addition to analgesics, pain may also contribute to the development of postoperative cognitive dysfunction [20-22]. The relatively less postoperative pain in patients receiving general anesthesia LMA and nerve block might be a reason for the higher MMSE scores in this group of patients.

During postoperative $72 \mathrm{~h}$, there were 3 cases of respiratory infection in the group of general anesthesia with intubation. However, none of the patients had respiratory infection in the general anesthesia with LMA/ nerve block group, and only 1 patient had this condition in the combined spinal-epidural anesthesia group. Although no airway device was used in the combined spinal-epidural anesthesia group, still 1 case of respiratory infection occurred in this group. This might be related to the high level of anesthesia and respiratory paralysis. Intratracheal intubation is more invasive than LMA and may increase the risk of respiratory infection. Two meta-analysis showed that LMA is superior to, or as good as, intratracheal intubation regarding respiratory infection $[23,24]$.
Our study is not without limitations. First, the sample size is small. Second, our study is a single-center study and may lack representativeness. Third, data was collected from a short postoperative period.

In conclusion, general anesthesia with LMA and nerve block was associated with less postoperative pain and less disturbances on intraoperative hemodynamics and postoperative cognitive function for elderly patients undergoing intertrochanteric fracture surgeries. LMA might also be associated with reduced risks of respiratory infection.

\section{Abbreviations \\ ASA: American Society of Anesthesiologists; LMA: Laryngeal mask airway; MMSE: Mini-Mental State Exam; VAS: Visual analog scale}

\section{Acknowledgements}

Not applicable.

\section{Authors' contributions}

$Y L, M S, W L$, and $H Y$ collected and analyzed the data. CY analyzed the data and drafted the manuscript. All authors read and approved the final manuscript.

\section{Funding}

No funding was received for this study.

Availability of data and materials

The datasets used and/or analyzed during the current study are available from the corresponding author on reasonable request.

Ethics approval and consent to participate

Our study was approved by the Ethics Committee of Chengdu Aerospace Hospital (No. 201700012).

Consent for publication

Not applicable.

\section{Competing interests}

The authors declare that they have no competing interests.

\section{Author details}

${ }^{1}$ Department of Orthopedics, Chengdu Aerospace Hospital, Chengdu 610100, China. '2Department of Anesthesia, Chengdu Aerospace Hospital, Chengdu 610100, China.

Received: 16 October 2019 Accepted: 8 December 2019

Published online: 17 December 2019

\section{References}

1. Gragasin FS, Bourque SL, Davidge ST. Vascular aging and hemodynamic stability in the intraoperative period. Front Physiol. 2012;3:74. 
2. Li L, Wang Z. Ovarian Aging and Osteoporosis. Adv Exp Med Biol. 2018; 1086:199-215.

3. Major $\mathrm{K}$, et al. Unknown osteoporosis in older patients admitted to postacute rehabilitation. Aging Clin Exp Res. 2019. https://doi.org/10.1007/ s40520-019-01302-7.

4. Neuman MD, et al. Anesthesia technique, mortality, and length of stay after hip fracture surgery. Jama. 2014;311(24):2508-17.

5. Chen WQ, et al. General laryngeal mask airway anesthesia with lumbar plexus and sciatic block provides better outcomes than general anesthesia and endotracheal intubation in elderly patients undergoing hip surgery. Arch Gerontol Geriatr. 2018;78:227-32.

6. Chi YL, et al. Evaluation of the postoperative cognitive dysfunction in elderly patients with general anesthesia. Eur Rev Med Pharmacol Sci. 2017; 21(6):1346-54.

7. Ezhar Y, D'Aragon F, Echave P. Hemodynamic responses to tracheal intubation with Bonfils compared to C-MAC videolaryngoscope: a randomized trial. BMC Anesthesiol. 2018;18(1):124.

8. Kondo $\mathrm{Y}$, et al. Relationship between changes in regional cerebral blood volume and oxygenation and changes in cardiac output and systemic vascular resistance during spinal anesthesia in women undergoing cesarean section. J Anesth. 2019;33:579-86.

9. Hofhuizen C, et al. Spinal anesthesia-induced hypotension is caused by a decrease in stroke volume in elderly patients. Local Reg Anesth. 2019;12:19-26.

10. Saranteas T, et al. The Utility of Echocardiography for the Prediction of Spinal-Induced Hypotension in Elderly Patients: Inferior Vena Cava Assessment Is a Key Player. J Cardiothorac Vasc Anesth. 2019;33(9):2421-7.

11. Song $Z$, et al. Comparison of laryngeal mask airway and endotracheal intubation in gynecological cancer operation. Oncol Lett. 2019;17(2):2344-50.

12. Mao $\mathrm{S}$, et al. A comparison between laryngeal mask airway and endotracheal intubation for anaesthesia in adult patients undergoing NUSS procedure. J Thorac Dis. 2018;10(6):3216-24.

13. Kilaru P, et al. Postoperative Cognitive Dysfunction in Indian Patients Undergoing Total Knee Replacement Under Spinal Anesthesia. Anesth Essays Res. 2018;12(1):116-8.

14. Konishi $Y$, et al. Postoperative cognitive dysfunction after sevoflurane or propofol general anaesthesia in combination with spinal anaesthesia for hip arthroplasty. Anaesth Intensive Care. 2018;46(6):596-600.

15. Kulason $\mathrm{K}$, et al. Indication of Cognitive Change and Associated Risk Factor after Thoracic Surgery in the Elderly: A Pilot Study. Front Aging Neurosci. 2017;9:396.

16. Zhang J, et al. Analysis of postoperative cognitive dysfunction and influencing factors of dexmedetomidine anesthesia in elderly patients with colorectal cancer. Oncol Lett. 2019;18(3):3058-64.

17. Li LQ, et al. Effects of dexamethasone on post-operative cognitive dysfunction and delirium in adults following general anaesthesia: a metaanalysis of randomised controlled trials. BMC Anesthesiol. 2019;19(1):113.

18. Yan W, Mao H, Qiu P. Effects of different analgesia regimens on early postoperative cognitive dysfunction in elderly patients undergoing radical resection of cervical carcinoma. Exp Ther Med. 2019;18(2):1465-9.

19. Ezhevskaya AA, et al. Relationship among anesthesia technique, surgical stress, and cognitive dysfunction following spinal surgery: a randomized trial. J Neurosurg Spine. 2019:1-8. https://doi.org/10.3171/2019.4.SPINE184.

20. Wang $Y$, et al. The effects of postoperative pain and its management on postoperative cognitive dysfunction. Am J Geriatr Psychiatry. 2007;15(1):50-9.

21. Kraychete DC, et al. Postoperative persistent chronic pain: what do we know about prevention, risk factors, and treatment. Braz J Anesthesiol. 2016; 66(5):505-12.

22. Gu H, et al. Preoperational chronic pain impairs the attention ability before surgery and recovery of attention and memory abilities after surgery in non-elderly patients. J Pain Res. 2019;12:151-8.

23. Li L, et al. The impact of laryngeal mask versus other airways on perioperative respiratory adverse events in children: A systematic review and meta-analysis of randomized controlled trials. Int J Surg. 2019;64:40-8,

24. de Carvalho ALR, et al. Laryngeal Mask Airway Versus Other Airway Devices for Anesthesia in Children With an Upper Respiratory Tract Infection: A Systematic Review and Meta-analysis of Respiratory Complications. Anesth Analg. 2018;127(4):941-50.

\section{Publisher's Note}

Springer Nature remains neutral with regard to jurisdictional claims in published maps and institutional affiliations.

\section{Ready to submit your research? Choose BMC and benefit from:}

- fast, convenient online submission

- thorough peer review by experienced researchers in your field

- rapid publication on acceptance

- support for research data, including large and complex data types

- gold Open Access which fosters wider collaboration and increased citations

- maximum visibility for your research: over $100 \mathrm{M}$ website views per year

At BMC, research is always in progress.

Learn more biomedcentral.com/submissions 